\title{
Model for Estimation Urban Transportation Supply-Demand Ratio
}

\author{
Chaoqun Wu, ${ }^{1,2}$ Yulong Pei, ${ }^{3}$ and Jingpeng Gao ${ }^{4}$ \\ ${ }^{1}$ School of Transportation Science and Engineering, Harbin Institute of Technology, Harbin 150090, China \\ ${ }^{2}$ School of Automobile and Traffic Engineering, Heilongjiang Institute of Technology, Harbin 150050, China \\ ${ }^{3}$ Traffic College, Northeast Forestry University, Harbin 150040, China \\ ${ }^{4}$ College of Information and Communication Engineering, Harbin Engineering University, Harbin 150001, China
}

Correspondence should be addressed to Chaoqun Wu; wuchaoqunwcq@126.com

Received 24 January 2015; Revised 30 June 2015; Accepted 24 August 2015

Academic Editor: Chronis Stamatiadis

Copyright (C) 2015 Chaoqun Wu et al. This is an open access article distributed under the Creative Commons Attribution License, which permits unrestricted use, distribution, and reproduction in any medium, provided the original work is properly cited.

\begin{abstract}
The paper establishes an estimation model of urban transportation supply-demand ratio (TSDR) to quantitatively describe the conditions of an urban transport system and to support a theoretical basis for transport policy-making. This TSDR estimation model is supported by the system dynamic principle and the VENSIM (an application that simulates the real system). It was accomplished by long-term observation of eight cities' transport conditions and by analyzing the estimated results of TSDR from fifteen sets of refined data. The estimated results indicate that an urban TSDR can be classified into four grades representing four transport conditions: "scarce supply," "short supply," "supply-demand balance," and "excess supply." These results imply that transport policies or measures can be quantified to facilitate the process of ordering and screening them.
\end{abstract}

\section{Introduction}

This paper describes a methodology for estimating the value of urban transportation supply-demand ratio, TSDR for short, that is the result of interaction between transport system support capacity and inhabitants' travel requests and can determine whether transport conditions are balanced.

In a multitude of papers, travel demand and transportation supply are shown to act as a means of traffic phenomenon analysis to shed light on the theories and techniques underlying high-effect transportation.

There are several popular theories deriving from supply and demand consideration. For example, kinematic wave theories of lane-changing traffic flow [1] and merging traffic flow [2] have been described by Jin. Microsimulation models have emphasized both day-to-day and within-day variability in both demand and supply dynamic condition for real-time transport strategies in automated highway and responsive traffic signal control systems [3]. Considering that transport supply and demand varied incessantly under the influence of travel time-variations [4], a theoretical framework for designing a reliable transportation network [5] was developed and formulated as a bilevel program, with the upper level specifying the objective with respect to the optimized subject to demand growth and economic constraints and the lower comprised of time-dependent use of equilibrium models. After calibrating all demand and supply parameters, a dynamic traffic assignment model for highly congested urban networks required a modified treatment of acceptance capacity [6]. Under stochastic demand and supply, a robust traffic assignment process of the expected residual minimization model places emphasis on the planner's perspective and stochastic cell transmission model [7] and can capture the mean and standard deviation (SD) of density of the traffic flow and the propagation of $\mathrm{SD}$ over time and space.

A variety of transport problems originating from the contradiction between travel demand and transportation supply have been discussed in the relational literatures. To tackle taxi service refusal [8], pricing policies and regulations should take into consideration its impact on demand-supply equilibrium in both monopolistic and competitive market. Empirical examination, based on data from a survey of the "parking marketplace" site around the UK's 25 busiest passenger airports, indicated that some car parking requirements in 
TABLE 1: Characteristic of complex system and transportation system.

\begin{tabular}{ll}
\hline $\begin{array}{l}\text { Complex system [20] } \\
\text { characteristic }\end{array}$ & Transportation system characteristic \\
\hline $\begin{array}{l}\text { Large numbers of elements } \\
\text { are manifold }\end{array}$ & $\begin{array}{l}\text { Elements: } \\
\text { People (drivers, passengers, and pedestrian) } \\
\text { Vehicle (motor and nonmotor vehicle, train) } \\
\text { Facilities (road, tunnel, bridge, signal system, etc.) } \\
\text { Management (laws and regulations, management technique) } \\
\text { Environment (economic and culture) }\end{array}$ \\
\hline $\begin{array}{l}\text { Interaction among the } \\
\text { elements is more important } \\
\text { than the element itself }\end{array}$ & $\begin{array}{l}\text { The crux of transportation system's maximum efficiency is the coordination of the elements } \\
\text { Multiple causality among } \\
\text { the elements }\end{array}$ \\
\hline & $\begin{array}{l}\text { Transportation system consists of subsystems such as economy, number of vehicles, environment, } \\
\text { travel demand, transport supply, and a traffic congestion subsystem. Every subsystem has } \\
\text { causality and there is special causality among the subsystems [21] }\end{array}$ \\
\hline $\begin{array}{l}\text { Transportation system's elements are in a stochastic condition; that is, they vary with time and } \\
\text { space; their linear relationship, because of complex causality, cannot satisfy the requirements of } \\
\text { modeling to simulate real transportation, so the modeling method has undergone several } \\
\text { processes: statistics, differential equations, system dynamic, the models of complex network, and } \\
\text { modeling method based on Agent [22] }\end{array}$ \\
$\begin{array}{l}\text { A transportation system, because of randomness and complexity, can only operate in orderly } \\
\text { fashion by using a self-feedback function. This is, in order for traffic flow tend to be in ordered } \\
\text { under certain conditions, the transportation system should self-adjust, based on real-time traffic } \\
\text { status, by control and management technologies [23], so that it has self-organization and } \\
\text { self-adaptiveness }\end{array}$ \\
\hline $\begin{array}{l}\text { Self-organization and } \\
\text { self-adaptiveness }\end{array}$
\end{tabular}

the airport would be experiencing rapid growth with a relatively small supply of overall airport parking, so airport operators and local authorities should be cognizant of the necessity of alternative parking provision [9]. A model analyzed the vicious cycle of a bus line [10], in which high demand will induce the operator to increase supply, in turn resulting in a higher level-of-service requirement and a subsequent increase in passenger numbers, triggering another round of service improvements.

The theories and techniques mentioned above can be aimed at any part of the transportation system that could make greater contribution. The question of whether transport supply and travel demand influence the whole transportation system has also been discussed.

Travel demand and transportation supply modeling methodology was presented through an Upper-Silesian Conurbation in Poland [11] example. To agglomerate them, the Interval Fractional Transportation Problem has adopted the expression of intervals with left and right limits [12]. Supplydemand equilibrium [13] has been discussed in terms of a hypernetwork (an abstract network on which a route was chosen) in the disaggregate demand models on a mathematically consistent basis for congested transportation systems. The new method of estimating the effect of travel demand variation and link capacity degradation was applied in the expected reliability of a roadway network: travel time reliability and capacity reliability [14].

The demand of transportation can be generally defined in terms of inhabitant trips, but the supply aspect had different assumptions according to the object or the aim. While route choice was regarded as a supply aspect of the urban network, the supply curves [15] were sensitive to the temporal and spatial distribution of demand, and its shape also differed from Origin-Destination movements within a given network; activity-based modeling and dynamic traffic assignment were combined [16] and the benefit of responsive pricing and travel information was quantified [17]. By improving bus and metro capacities contributing to the transportation supply, a framework for evaluating the dynamic impacts of a congestion pricing policy [18] can show how supply dynamics affect the travel demand of individuals and their choice of different transportation modes, and the method [19] of design and implementation of efficient transit networks can be applied to designing a high-performance bus network in Barcelona (Spain).

The above literatures are aimed at developing solution or a corresponding theory for a transport problem. However, because the various parts of transportation systems are interactive, the solution of a transport problem is bound to bring up new problems, so this paper proposes a macroscopic analysis method for estimating the TSDR.

\section{Previous Work}

2.1. Methods and Tools. A transportation system is an open complex system, and Table 1 describes the characteristic of complex system and transportation system. Peer experts have applied the theories and methods of system engineering in their approaches for modeling in the transportation area.

System dynamics is an approach to understanding the behavior of complex systems over time, and it is able to deal with internal feedback loops and time delays that affect the behavior of an entire system. This approach was well-suited to 


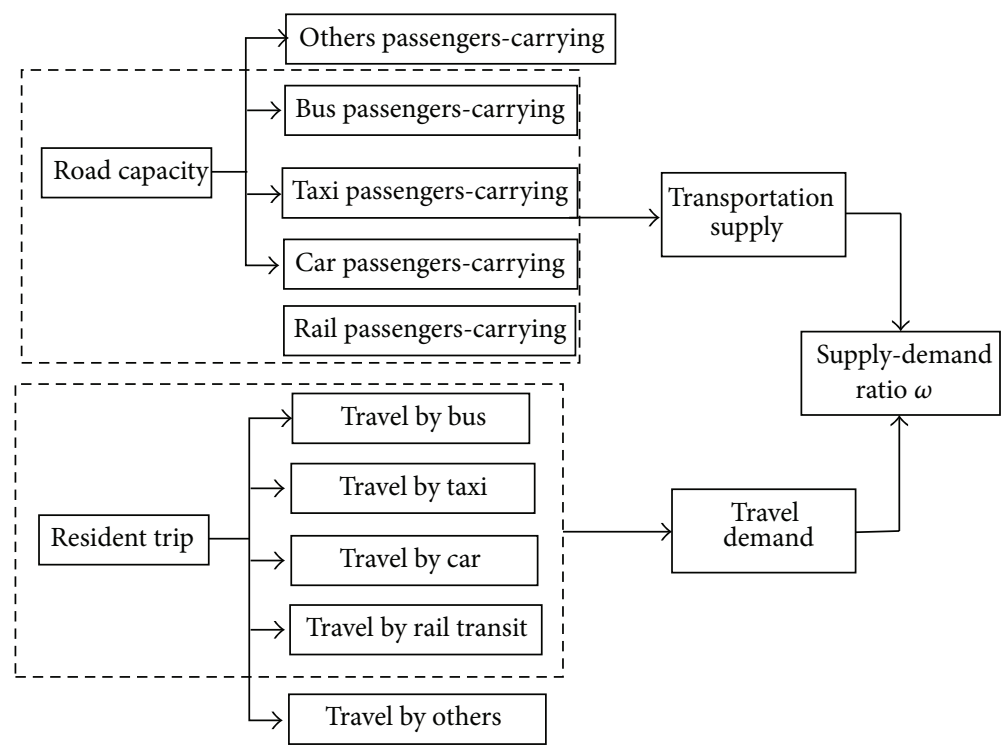

FiguRE 1: Idealized system of urban transport system.

strategic issues and could provide a useful tool for supporting policy analysis and decision-making in the transportation field [24]. The areas of application include the take-up of alternate fuel vehicles, supply chain management affecting transport, highway maintenance, strategic policy, and a set of emerging application areas.

This paper analyzes the transportation system using the methods of system dynamics and will estimate the TSDR by VENSIM, an industrial-strength simulation software package for improving the performance of real systems; it has a rich feature set emphasizing model quality, connections to data, flexible distribution, and advanced algorithms.

\subsection{The Idealize System. As stated in Transportation System} Analysis [25], "a transportation system is a collection of elements and the interactions between them that produce both the demand for travel in a given area and the provision of transportation services to satisfy this demand." In other words, the transportation system consists of two main components: travel demand and transportation supply. Figure 1 depicts the idealized system studied in the paper.

(1) Transportation Supply. The transportation supply component as described in Transportation System Analysis [25] is made up of facilities (roads, parking spaces, railway lines, etc.), services (transit lines and timetables), regulations (road circulation and parking regulations), and prices (transit fares, parking prices, road tolls, etc.) that produce travel opportunities.

This is to say that the purpose of measures such as constructing transport facilities, improving services, strengthening management, and pricing reasonably is to offer additional travel service. It is then necessary that transportation supply is quantized by the maximum passenger-carrying capacity of the transport system per unit time. This leads to Definition 1.
Definition 1. Transportation supply is the maximum amount of passenger-carrying capacity contributed by the metropolitan's transport system; it has three characteristics: resources restriction, multiformity of transport modes, and multilevels of service targets. Transportation supply and demand have settled into dynamic equilibrium.

The facilities for mass transit in China include urban road, rail transit, and ferry; rail transit mainly includes tram, light rail, rapid rail (metro), monorail, and funicular. Ferry and funicular play an auxiliary role in some cities with special geography conditions such as a river passing through or mountainous composition of the city's landform; tram generally cannot exist in Chinese cities because of ever more crowded transport. Almost all of the rail transit entities operate independently in underground tunnels or on viaducts so as not to interfere with surface transport, so Hypothesis 2 can be given.

Hypothesis 2. There are two transport facilities for metropolitan inhabitant: urban road and rail transit, and both coexist and are independent of one another.

Most often, types of motorized and nonmotorized vehicles operating on urban roads include bus, car, truck, motorcycle, and bicycle; their purpose and travel times vary so traffic composition varies with city limits and times. Because trucks were forbidden in the daytime in most urban districts, cargo traffic's influence on the transportation supply and travel demand balance can be overlooked in the daytime. Buses, disaggregated by purpose, are composed of public buses, commuter buses, and intercity buses; the latter two are a minority on urban roads and have flexibility for choosing congestion-free routes, so "bus" will refer specifically to public buses to simplify the model. Motorcycles and bicycles are suitable for traveling short distances but rarely run on 
TABLE 2: Information for chosen cities.

\begin{tabular}{|c|c|c|c|c|c|}
\hline $\begin{array}{l}\text { Metropolitan } \\
\text { area }\end{array}$ & Year & Population (million) & $\begin{array}{l}\text { Gross Domestic } \\
\text { Product (billion, } \\
\text { RMB) }\end{array}$ & Urban area $\left(\mathrm{Km}^{2}\right)$ & Significant transport event \\
\hline Beijing & 2011 & 20.186 & $1,625.19$ & 8579 & \\
\hline Tianjin & 2011 & 13.546 & $1,130.73$ & 1103 & \\
\hline Shanghai & 2011 & 23.475 & $1,919.57$ & 9589 & \\
\hline Guangzhou & 2012 & 8.223 & $1,355.12$ & 2910 & \\
\hline Hangzhou & 2013 & 7.253 & 780.20 & 2060 & \\
\hline Shenzhen & 2012 & 1.047 & $1,150.55$ & 5256 & \multirow{2}{*}{$\begin{array}{l}\text { The } 181 \mathrm{~km} \text { new road and the } \\
133 \mathrm{~km} \text { reformed road in } 2012\end{array}$} \\
\hline Shenzhen & 2013 & 1.055 & $1,295.00$ & 5282 & \\
\hline Shenyang & 2012 & 8.228 & 660.68 & 1504 & \multirow{3}{*}{$\begin{array}{l}\text { Metro line } 1 \text { and line } 2 \text { opened, } \\
\text { respectively, on September 27, } \\
\text { 2011, and February 9, } 2012\end{array}$} \\
\hline Shenyang & 2011 & 7.227 & 591.49 & 1495 & \\
\hline Shenyang & 2010 & 7.196 & 501.71 & 1485 & \\
\hline Nanjing & 2012 & 8.161 & 720.16 & 1215 & \\
\hline
\end{tabular}

${ }^{{ }^{*}}$ These data from China City Statistical Yearbook.

the expressway and major arterial roads because of the great distances between workplace and home in metropolitan areas. "Car" comes in three forms: private car, official vehicle, and taxi; the first two have similar traits [26] and the characteristics of taxi trips [27] are, dynamically using road resources, different from the former two. So, Hypothesis 3 is given.

Hypothesis 3. Traffic composition on urban roads consists of car, public bus, and taxi; the term "car" includes both private cars and official vehicles.

(2) Travel Demand. Travel demand, also described in Transportation System Analysis [25], derives from the need to access urban functions and services in different places and is determined by the distribution of households and activities within the area.

Travel demand is trip need or expectation of a city inhabitant for business or entertainment and is the natural outgrowth of economic development and urban population increase. It is always reflected in the trip structure of the metropolitan area, combined into several trip modes such as car, bus, taxi, rail transit, bicycle, and walking. The impact factors that affect travel mode choices of urban residents derive from the spatial and temporal nonuniformity of transport facilities' use, the purpose of people trips, and the convenience of the transport system, so Definition 4 applies. In the meantime, Hypothesis 5 can be deduced from Hypotheses 2 and 3.

Definition 4. Travel demand is the movement requirement using public transport facilities from one functional area to another; it varies with the spatial and temporal nonuniformity of transport facilities' use, the purpose-sets of people trips, and the convenience-sets of the transport system. Transportation demand can be measured by the total number of trips.

Hypothesis 5. The trip structure within the metropolitan area can be characterized by four trip modes: car, public bus, taxi, and rail transit. The "car" designation includes both private cars and official vehicles.

2.3. Data. This study examined certain cities that exhibited one of the two characteristics listed below. Table 2 gives specific information about these cities.

(a) The cities are densely populated and relatively welldeveloped economically so they use superior transportation systems and are able to provide sets of data representing different traffic states for quantitative analysis.

(b) Significant transport events occurred in recent years; examples would include the Shenyang metro being in operation and Shenzhen's new and reformed long urban road. The before-and-after data comparison can reveal an event's impact on the balance of the transportation system.

The sources of the micro- and macrodata involved in this paper are mainly focused on the following ways.

(a) The Official Data. They include China City Statistical Yearbook, Yearbook of China Integrated Transport, and the existing data from the Internet published by municipal transportation commissions.

The digital information from China City Statistical Yearbook had macroeconomic messages (including population and Gross Domestic Product), investment amounts in transportation from government, divergence of residents' earnings, urban road grades and their lengths, and distribution of the vehicles' owners. Information from the Yearbook of China Integrated Transport provided the total number of resident trips, the distribution of travel modes, the vehicle speed in road net, the lengths of urban roads classified, the operational information about public bus and railway routes (kilometrage, number of operating vehicles, and passengers 


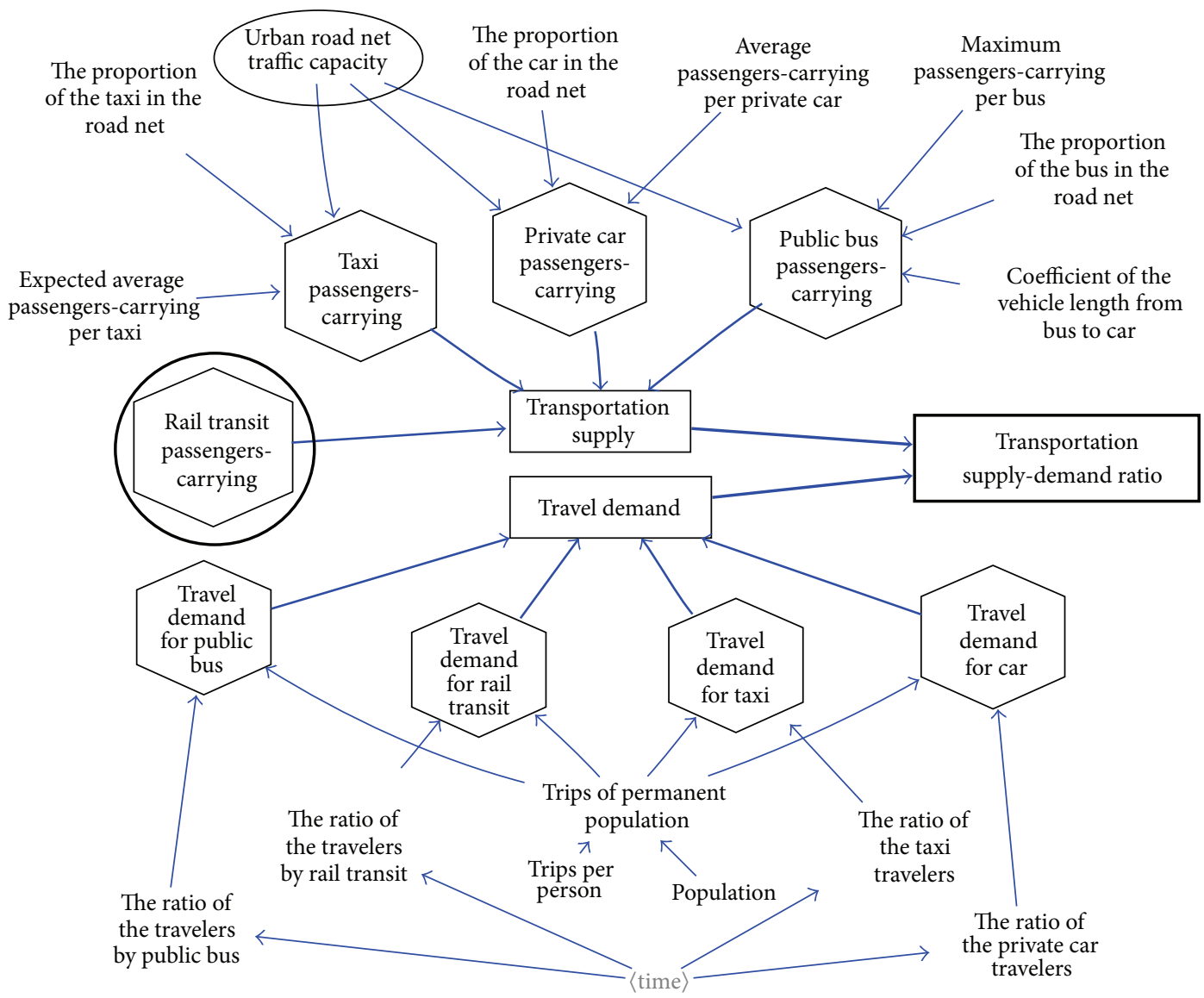

FIGURE 2: Urban TSDR estimating framework.

carried), and so on. The municipal transportation commission published operating information about railway, public bus, and taxi in real time.

(b) The Data from the Traffic Administrative Department of the Public Security Organ and the Public-Transport Operation Corporation. Traffic monitoring systems and transportation information collection systems set up in Chinese cities provide traffic microdata such as traffic flow, headway, traffic density, and speed, which can be used for estimating Lanes Comprehensive Utility Coefficient and Intersections Effective Utility Coefficient of classified roads.

The operational data from the public-transport operation corporation (bus, metro, or taxi operation company) includes not only passengers carried but also Passenger Load Factor, OD (Origin and Destination), and kilometrage of the passengers, used both in directly estimating the supply-demand ratio and reciprocally verifying with official statistics.

(c) Surveying on the Spot. The purpose of surveying on spot in a city was to gain the necessary data that cannot be obtained by the above two modes; this includes vehicles average travel distance, the respective proportion of the public buses, taxis, and cars in the urban road, and their average number of passengers carried.

Manual records and interview surveys were adopted. The proportion of public buses, taxis, cars and their Average
Carried Passengers were manually recorded in forty sections of expressway, major arterial road, minor arterial road, and collector streets during peak hours and off-peak hours during both working days and Sunday. In a roadside interview survey, at least 200 drivers in a city were asked, "Normally, how many kilometers do you drive a day"; the vehicles average travel distance was the average value of these answers.

\section{Model}

The transportation supply-demand ratio used to quantitatively describe the transport system state is the ratio between transportation supply and travel demand, that is, between the maximum amount of passengers carried and the total trips according to Definitions 1 and 4 . As the value of this ratio increases, urban transport would become more and more unobstructed.

3.1. Model for Estimating Urban TSDR. Figure 2 shows the supply-demand ratio estimating framework. Letting $\omega$ denote the TSDR and letting $S$ and $D$ separately denote transport supply and travel demand, the estimating model can be written as

$$
\omega=\frac{S}{D}
$$


(1) Transportation Passengers-Carrying Supply. In Figure 2, the transportation passengers-carrying supply $S$ is composed of travelers carried by public bus $S_{\text {bus }}$, rail transit $S_{\text {rail }}$, taxi $S_{\text {taxi }}$, and car $S_{\text {car }}$, resulting in

$$
S=S_{\text {bus }}+S_{\text {rail }}+S_{\text {taxi }}+S_{\text {car }} \text {. }
$$

By Hypothesis 2, the bus passengers-carrying supply $\left(S_{\text {bus }}\right)$, taxi passengers-carrying supply $\left(S_{\text {taxi }}\right)$, and car passengers-carrying supply $\left(S_{\text {car }}\right)$ are limited by net urban road traffic capacity $C_{\text {roadnet }}$. By Hypothesis 3 , the traffic capacity of urban road net $C_{\text {roadnet }}$ and the rail passengers-carrying supply $S_{\text {rail }}$, as shown by the circled section in Figure 2, are independent of one another, and they will be separately introduced in Sections 3.2 and 3.3.

Considering that the traffic capacity unit of measurement is the PCU (Passenger Car Unit), the mathematical formulation of bus passengers-carrying supply $S_{\text {bus }}$ after vehicle equivalent conversion can be stated as

$$
S_{\text {bus }}=\frac{C_{\text {roadnet }} \times \alpha}{\phi} \times D_{\text {bus }}^{\max },
$$

where $\alpha=$ the proportion of the bus in the road net; $\phi=$ conversion coefficient of the vehicle length form bus to car; $D_{\text {bus }}^{\max }=$ maximum passengers-carrying per bus, restricted by the transport policies grounding in service-level oriented or transportation-capacity oriented.

Similarly, taxi passengers-carrying supply $S_{\text {taxi }}$ can be expressed as the product of the average expected passengerscarrying per taxi and the number of the taxies, so

$$
S_{\text {taxi }}=C_{\text {roadnet }} \times \beta \times D_{\text {taxi }}^{a} \text {, }
$$

where $\beta=$ the proportion of taxis in the road net and $D_{\text {taxi }}^{a}=$ average expected ridership per taxi, dependent on whether carpooling is permitted.

The car passenger-carrying supply $S_{\text {car }}$ is also related to the number of cars and average passenger-carrying per car, so

$$
S_{\text {car }}=C_{\text {roadnet }} \times \gamma \times D_{\text {car }}^{a},
$$

where $\gamma=$ the proportion of private cars in the road net; $D_{\mathrm{car}}^{a}=$ average passenger-carrying per car.

(2) Travel Demand. Trip demand $D$ is the sum of trip demand for bus, rail transit, taxi, and car and similarly to the transportation passenger-carrying supply estimating process it can be expressed by the mathematical formula

$$
D=D_{\text {bus }}+D_{\text {rail }}+D_{\text {taxi }}+D_{\text {car }} \text {, }
$$

where $D_{\text {bus }}, D_{\text {taxi }}, D_{\text {rail }}$, and $D_{\text {car }}$ are, respectively, trip demand for bus, taxi, rail transit, and car. They are expressed by the ratios of their travelers to the total, so these equations are

$$
\begin{aligned}
& D_{\text {bus }}=P A R_{\text {bus }}, \\
& D_{\text {taxi }}=P A R_{\text {taxi }}, \\
& D_{\text {rail }}=P A R_{\text {rail }}, \\
& D_{\text {car }}=P A R_{\text {car }},
\end{aligned}
$$

where $P$ is the total population in the city; $A$ is average trip; and $R_{\text {bus }}, R_{\text {taxi }}, R_{\text {rail }}$, and $R_{\text {car }}$ are the proportion of bus, taxi, rail transit, and car travelers in the total trips.

(3) Passengers-Carrying Supply-Demand Ratio (PCSDR). To embody the urban transport system supply-demand relation, if the values of the four modes' passengers-carrying supplydemand ratio, PCSDR for short, are estimated at the same time, then

$$
\begin{aligned}
& \omega_{\text {bus }}=\frac{S_{\text {bus }}}{D_{\text {bus }}}, \\
& \omega_{\text {rail }}=\frac{S_{\text {rail }}}{D_{\text {rail }}} \\
& \omega_{\text {taxi }}=\frac{S_{\text {taxi }}}{D_{\text {taxi }}}, \\
& \omega_{\text {car }}=\frac{S_{\text {car }}}{D_{\text {car }}} .
\end{aligned}
$$

3.2. Urban Road Net Traffic Capacity. The traffic capacity of the urban road net is the maximum number of vehicles running on the urban road net at a certain time; it is limited by the characteristics of the net and the traffic conditions. Figure 3 shows its estimation module.

All the transportation modes except rail transit are restricted to the urban road net traffic capacity. And urban road net traffic capacity [28] $C_{\text {roadnet }}$ is expressed by the ratio of the spatial and temporal resources of road net $\mathrm{RE}_{d}$ to the spatial and temporal consumption of traffic unit $\mathrm{RE}_{t}$ based on the Specific Vehicle Saturation $\rho$; it takes the form

$$
\begin{aligned}
C_{\text {roadnet }}= & \frac{\mathrm{RE}_{d}}{\mathrm{RE}_{t}} \times \rho \\
= & \left(\sum_{i=1}^{4} L_{i} \cdot d_{i} \cdot \eta_{1 i} \cdot \eta_{2 i}\right) \times T \\
& \times \frac{1000}{\left(l_{p} / V\right)\left((t / 3.6) V+l_{v}+l_{s}\right)} \times \rho,
\end{aligned}
$$

where $i=1,2,3,4$, respectively, replace the expressway, major arterial road, minor arterial road, and collector street and $L_{i}=$ length of the roads classified. Its value is calculated by the investment or use existing data. $\eta_{1 i}=$ Intersections Effective Utility Coefficient (IEUC) for roads of each grade; $\eta_{2 i}=$ Lanes Comprehensive Utility Coefficient (LCUC) for roads of each grade; $T=$ service time, $\mathrm{h} ; L_{p}=$ vehicles average travel distance, $\mathrm{km} ; V=$ vehicles average travel speed, $\mathrm{km} / \mathrm{h}$; $t=$ driver's reaction time, $\mathrm{s} ; l_{v}=$ car length, $\mathrm{m} ; l_{s}=$ minimum safe distance between two cars when they are static, $\mathrm{m}$.

In the above formulas, many parameters may change in implementation of transport policies or measures, so the estimated result of the model can reflect the effect of such changes. For example, investment in transportation may cause length of the roads classified and length of rail transit line increase. By using and generalizing advanced technology like Intelligent Transportation Systems, driver Information 


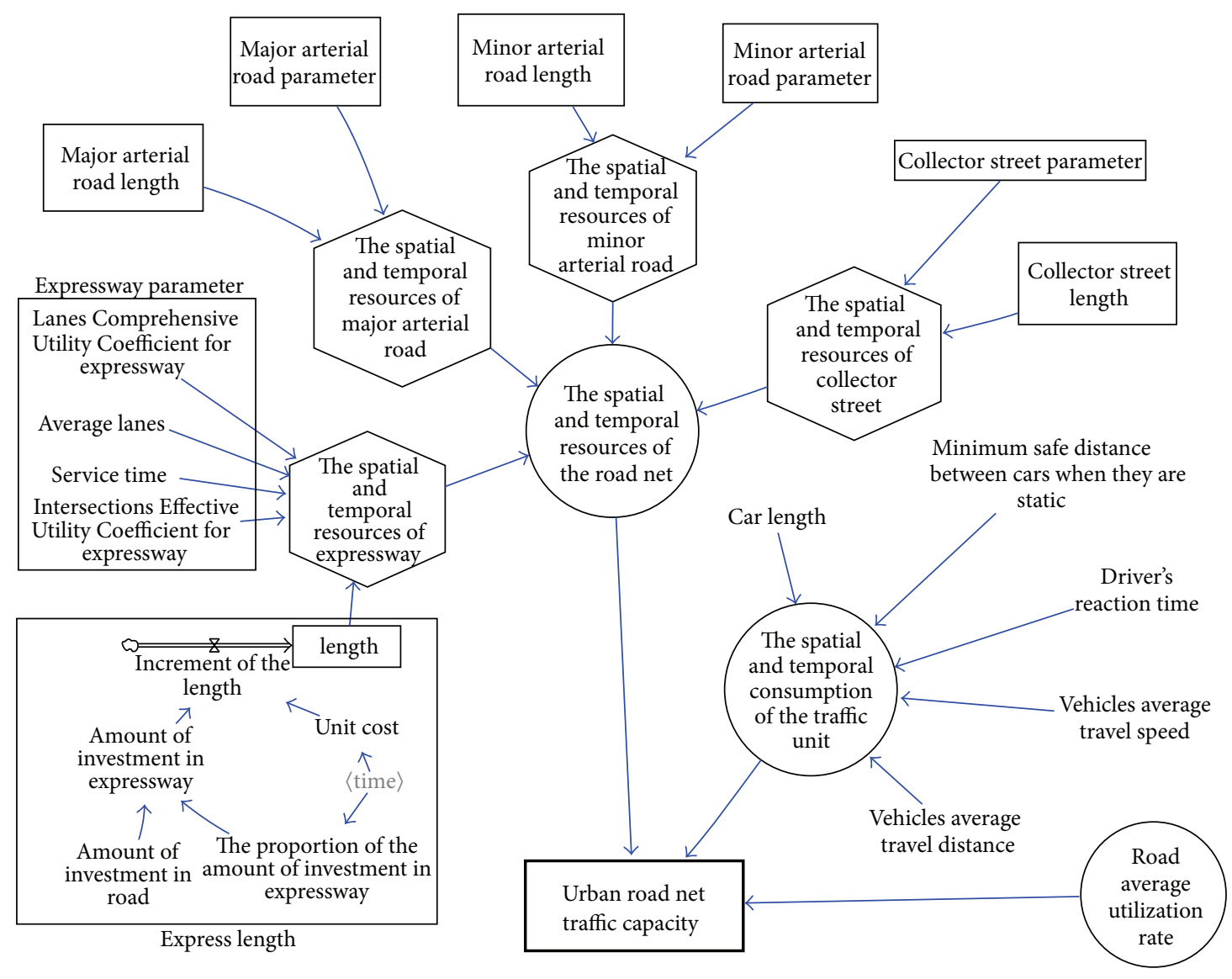

FIGURE 3: Estimation module for traffic capacity of urban road net.

System, urban Traffic Area-wide Cooperation Control Systems, and Urban Pedestrian Systems the values of Intersections Effective Utility Coefficient and Lanes Comprehensive Utility Coefficient will increase.

The values of IEUC and LCUC for roads classified are displayed by Time Occupancy [29]; that is, they are the percentage of all the time that vehicle occupied in road; then

$$
\eta_{1 i}\left(\eta_{2 i}\right)=\sum_{i=1}^{n} \frac{t_{i}}{T_{o}},
$$

where $T_{o}=$ observed duration, $t_{i}=$ time that number $i$ vehicle moves through the observed cross-section, and $n=$ number of the vehicles observed.

There are some things to be aware of while observing the IEUC and LCUC:

(i) One should try to choose the cross-sections less affected by intersections and the period during which the traffic becomes saturated.

(ii) The LCUC should be dissected for every lane.

(iii) Entries to the intersection while measuring the IEUC should be observed.

(iv) Select all types of the intersections and cross-sections, but not all of them. (v) IEUC and LCUC average aimed at the roads of each grade should be calculated.

Table 3 [29] lists the suggested values of IEUC and LCUC.

3.3. Rail Transit Passengers-Carrying Supply. The rail transit passengers-carrying supply $S_{\text {rail }}$ is expressed as a sum of all of the city's rail lines ridership capacity $\left(C_{i}\right)$, and it is strongly influenced by the Departing Interval $\left(I_{\text {rail }}\right)$ and Passengerscarrying per train $\left(N_{i}\right)$. Figure 4 describes the rail transit passengers-carrying supply estimating module.

Generally, the following formulas state the algorithmic method:

$$
\begin{aligned}
\mathrm{S}_{\text {rail }} & =\sum_{i=1}^{n}\left(C_{i} \times N_{i}\right), \\
C_{i} & =\frac{T}{I_{\text {rail }}} \times 3600 .
\end{aligned}
$$

(1) Departing Interval $\left(I_{\text {rail }}\right)$. In reality, the factors affecting the Departing Interval fall into two categories:

(i) those restricted by telecommunication and signal control technology, letting $I_{\text {rail }}^{\mathrm{min}}$ denote the minimum tracking interval dependent on the signaling system, whose value is provided by the manufacture of the rail line used, 
TABLE 3: Suggested values of IEUC and LCUC.

\begin{tabular}{lcccc}
\hline Urban road classification & Expressway & Major arterial road & Minor arterial road & Collector street \\
\hline $\begin{array}{l}\text { Intersections Effective } \\
\text { Utility Coefficient }\end{array}$ & 0.75 & $0.55 \sim 0.65$ & $0.45 \sim 0.55$ & $0.40 \sim 0.50$ \\
$\begin{array}{l}\text { Lanes Comprehensive } \\
\text { Utility Coefficient }\end{array}$ & 0.9 & $0.85 \sim 0.95$ & $0.80 \sim 0.90$ & $0.85 \sim 0.95$ \\
\hline
\end{tabular}

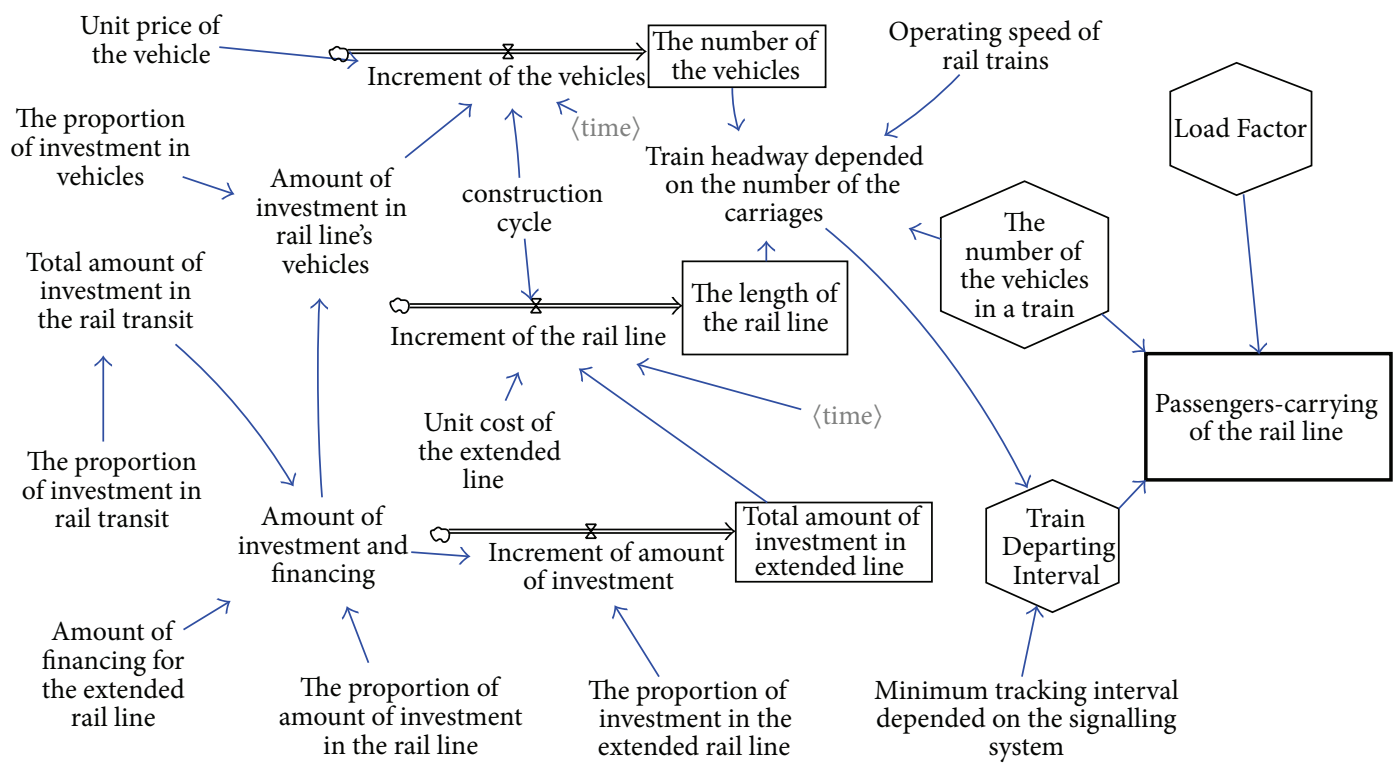

FIGURE 4: Estimated module for rail transit passengers-carrying supply.

(ii) those restricted by the horizontal and vertical curves of rail facilities and the number of the trains. The horizontal and vertical curves determine the train running speeds and the number of the trains supports the Departing Interval. Let $I_{\text {rail }}^{d}$ denote the Train Departing Interval dependent on the facilities, and the result is the turnaround time $\left(T_{t}\right)$ divided by the number of the trains $\left(N_{t}\right)$. The derivation is as follows:

$$
\begin{aligned}
I_{\text {rail }}^{d} & =\frac{T_{t}}{N_{t}}, \\
T_{t} & =\frac{2 L}{V}, \\
N_{t} & =\frac{M}{m},
\end{aligned}
$$

where $L=$ length of rail line; $V=$ average travel speed, $\mathrm{km} / \mathrm{h}$; $m=$ number of the vehicles in a train; $M=$ number of the vehicles.

In the model shown in Figure 4, the rail-line length and the vehicle number are calculated by investment; that is, their values after a construction cycle are determined based on the actual investment and the construction cost. The meaning of the method is a quantitative prediction of the implementation effect of policies like the investment focus and reducing the engineering cost; the construction cycle is generally 5 years or so. Certainly, they can either use the existing data for the existing line or define the measures.

After considering the ratio of the spare and maintaining trains to operating trains $(\tau)$, converting hours into seconds, substituting (13) and (14) into (12) produces

$$
I_{\text {rail }}^{d}=\frac{2 L}{V} \times \frac{m}{M} \times(1+\tau) \times 3600 .
$$

For the Departing Interval choose the max value between $I_{\text {rail }}^{\min }$ and $I_{\text {rail }}^{d}$, producing

$$
I_{\text {rail }}=\max \left\{I_{\text {rail }}^{d}, I_{\text {rail }}^{\mathrm{min}}\right\}
$$

(2) Passengers-Carrying per Train $\left(N_{i}\right)$. Since passengerscarrying per train depends on the prescribed passengerscarrying per vehicle $\left(D_{\text {rail }}\right)$ and Load Factor $(\sigma)$, then

$$
N_{i}=m \times D_{\text {rail }} \times \sigma .
$$

(3) Example Verification. To verify the rail transit passengerscarrying supply estimating framework, Table 4 lists the error rate of the estimated value compared with the actual value obtained in 2012 from the 15 Beijing subway lines.

In Table 4, most absolute values of the error rate are less than $3 \%$, and only values of Changing Line and Fangshan Line are greater than $3 \%$. The max value is $5.98 \%$, which was 
TABLE 4: Beijing subway passengers-carrying estimated verification in 2012.

\begin{tabular}{|c|c|c|c|}
\hline Rail line & $\begin{array}{c}\text { Passengers- } \\
\text { carrying } \\
\text { estimated } \\
\text { (person/hour) }\end{array}$ & $\begin{array}{l}\text { Passengers- } \\
\text { carrying in } \\
\text { reality } \\
\text { (person/hour) }\end{array}$ & Error rate (\%) \\
\hline Line 1 & 42336 & 42840 & -1.18 \\
\hline Line 2 & 37800 & 38556 & -1.96 \\
\hline Line 4 & 26779 & 26677 & 0.38 \\
\hline Line 5 & 31129 & 31328 & -0.64 \\
\hline Line 8 & 17640 & 17520 & 0.68 \\
\hline Line 9 & 11760 & 11680 & 0.68 \\
\hline Line 10 & 32072 & 32296 & -0.69 \\
\hline Line 13 & 33075 & 32130 & 2.94 \\
\hline Line 15 & 12027 & 11680 & 2.97 \\
\hline $\begin{array}{l}\text { Changping } \\
\text { Line }\end{array}$ & 13569 & 13140 & 3.26 \\
\hline Fangshan Line & 9284 & 8760 & 5.98 \\
\hline Yizhuang Line & 11386 & 11680 & -2.52 \\
\hline Batong Line & 29223 & 29988 & -2.55 \\
\hline $\begin{array}{l}\text { Airport } \\
\text { Express }\end{array}$ & 2680 & 2688 & -0.30 \\
\hline Daxing Line & 22800 & 22603 & 0.87 \\
\hline \multicolumn{3}{|c|}{ Average error rate (absolute value) } & 1.84 \\
\hline
\end{tabular}

${ }^{*}$ The data of passengers-carrying in reality from 2012 Yearbook of China Integrated Transport.

caused by reserved actual passengers-carrying of Fangshan Line that was early in the running. Thus the way of the rail transit passengers-carrying supply estimation is effective and feasible.

3.4. Passengers-Carrying Supply Estimation on Bus Lane. The bus lane is one of two types depending on whether it is independent of the urban road net:

(i) Open Up in the Road. This type of bus lane essentially occupies road resources, so the intersections and cross-sections with bus lanes are separated into dedicated lanes, permitting independent observations of the IEUC and LCUC.

(ii) Individually Built, That Is, Bus Rapid Transit (BRT). It is similar to rail transit and is determined to the rail transit passengers-carrying supply estimating framework.

\section{Estimation and Results}

In this section, fifteen groups' data were chosen from eight cities to analyze the TSDR. Table 5 separately lists the estimated values of the PCSDR of bus, taxi, rail, and car and the TSDR.

Theoretically, the value of supply-demand ratio is near 1: a value greater than 1 means that the supply exceeds the demand, and a value less than 1 means that the supply is short.
However, in view of the complexity of the metropolitan transport system and the limitation of the model, the PCSDR of bus, taxi, rail, and car is, respectively, determined, and its underlying causes are explored to lay a foundation for describing the transport conditions represented by the value range of the TSDR.

(1) Estimated Result of the PCSDR of Bus, Taxi, Rail, and Car during Peak Hours. During peak hours, the values of sample cities' TSDR, except for Hangzhou's, are less than 0.95, and four of these are lower than 0.8; the supply and demand for the bus, taxi, rail transit, and car, however, vary considerably.

It is common for the values of bus PCSDR to remain steady during the peak hour interval [30]. In spite of a support of the public bus priority policy, such as bus lanes and bus traffic signal priority, bus operation efficiency is still of concern in the worst road traffic situations. Buses, frequently running under acceleration, deceleration, and idling conditions, seldom arrive at predictable intervals and may be so crowded that passengers who must ride the bus must either contend with a crowded and throttling atmosphere or miss one connection after another following an unsuccessful struggle to aboard.

The values of taxi PCSDR are the largest, and they exceed 0.8 in the overwhelming number of major cities. Because the expectation of taxi is the lowest from perspectives of both supply and demand, on the supply side, taxi drivers try to avoid operation to reduce costs, especially under crowded traffic conditions, and on the demand side, passengers often do not choose taxis travel because of the higher trip charge (compared to bus) and the longer trip time (compared to rail transit).

Most of the values of car PCSDR are less than 0.8, especially for Beijing, just 0.22 during peak hours. From the Chinese standpoint, it may be essential to own private cars because families with children, the elderly, and the infirm must use cars as travel tools to avoid dealing with the congestion of urban public traffic. Other reasons for owning a car, a symbol of identity, might include winning more social respect and even bringing about more economic benefits. Therefore, when Beijing and Shanghai use lottery system to limit new vehicle registrations, vehicle possession still had respective increases of 225,000 and 59,000 in 2013 and reached totals of 5.2 and 2.8 million. Relative to urban road mileage, 28,608 and 17,316 kilometers, private car demand greatly exceeds the supply of urban road net, so excessively larger vehicle possession is the root cause of the urban road net congestion. On the other hand, the low average passengers-carrying, only 1.17 from survey data, is another important contributor to congestion.

The estimated values of rail PCSDR range wildly, from 0.37 to 1.01 , and the more developed the rail transit system becomes, the lower its value will be. In vast metropolitan subway networks (like those in Beijing, Shanghai, and Guangzhou), during peak hours a horde of people fight their way off the train while another such horde barely waits before fighting their way on, and the train can hardly get moving because of all the people crammed in and blocking doors; subway attendants help by shoving the last people onto the train. In 
TABLE 5: Estimated result on TSDR.

\begin{tabular}{|c|c|c|c|c|c|c|c|}
\hline City & Year & Time period & Bus PCSDR & Rail PCSDR & Taxi PCSDR & Car PCSDR & TSDR \\
\hline Beijing & 2011 & Peak hour in working day & 0.82 & 0.50 & 0.91 & 0.22 & 0.47 \\
\hline Guangzhou & 2010 & Peak hour in working day & 0.92 & 0.37 & 0.95 & 0.56 & 0.68 \\
\hline Shanghai & 2011 & Peak hour in working day & 0.81 & 0.57 & 0.93 & 0.60 & 0.69 \\
\hline Nanjing & 2012 & Peak hour in working day & 0.86 & 0.84 & 0.90 & 0.66 & 0.76 \\
\hline Tianjin & 2011 & Peak hour in working day & 0.83 & 0.96 & 0.86 & 0.76 & 0.81 \\
\hline Shenzhen & 2012 & Peak hour in working day & 0.94 & 0.70 & 1.03 & 0.77 & 0.84 \\
\hline Shenzhen & 2013 & Peak hour in working day & 0.97 & 0.71 & 0.98 & 0.90 & 0.92 \\
\hline Shenyang & 2010 & Peak hour in working day & 0.87 & - & 0.75 & 0.73 & 0.82 \\
\hline Shenyang & 2011 & Peak hour in working day & 0.88 & 0.90 & 0.75 & 0.75 & 0.83 \\
\hline Shenyang & 2012 & Peak hour in working day & 0.99 & 0.83 & 0.81 & 0.81 & 0.89 \\
\hline Hangzhou & 2013 & Peak hour in working day & 0.90 & 1.01 & 0.86 & 0.84 & 0.93 \\
\hline Beijing & 2011 & Off-peak hour in working day & 1.13 & 0.96 & 0.85 & 0.93 & 0.97 \\
\hline Beijing & 2011 & Weekend daytime & 1.09 & 0.96 & 1.00 & 0.90 & 1.02 \\
\hline Shanghai & 2011 & Weekend daytime & 1.07 & 1.12 & 0.96 & 1.05 & 1.06 \\
\hline Nanjing & 2012 & Weekend daytime & 1.10 & 1.18 & 1.17 & 1.13 & 1.13 \\
\hline
\end{tabular}

TABLE 6: Value range of the TSDR under different transport conditions.

\begin{tabular}{lll}
\hline Value range & Significance & Transport conditions \\
\hline$\omega \leq 0.8$ & Scarce supply & $\begin{array}{l}\text { Urban transport system cannot meet the challenge of residents travel: excessively } \\
\text { crowded rail transit and bus, severe congestion on the road net, and taxi shortage. }\end{array}$ \\
\hline & Short supply & $\begin{array}{l}\text { In the general case, urban transport system may meet the challenge of residents } \\
\text { travel. However, when a sudden event (even a small perturbation) or bad weather is } \\
\text { encountered, rail transit will be crowded, many roads will become jammed, and } \\
\text { buses will be delayed. In other words, the system has weak ability to withstand } \\
\text { disturbance. }\end{array}$ \\
\hline Supply-demand balance & $\begin{array}{l}\text { In most situations, urban transport systems can meet the challenge of residents } \\
\text { travel and have self-adjustment ability. When a sudden event or bad weather is } \\
\text { encountered, some roads will become jammed, and the number of rail and bus } \\
\text { passengers will increase. These disturbances will often be quelled in short times } \\
\text { without the interposition of managers. }\end{array}$ \\
\hline Excess supply & $\begin{array}{l}\text { Under any circumstances the urban transport system can meet the challenge of } \\
\text { residents travel. }\end{array}$ \\
\hline
\end{tabular}

spite of such conditions, more and more people are willing to choose subway travel because this is the only way to arrive at their destination on schedule. It is a kind of inevitable phenomenon that the demand for rail transit in Chinese cities will exceed the supply both now and in the future.

(2) Transport Conditions Represented by the Value Range of the TSDR. The TSDR's estimated values, listed in Table 5, range from 0.47 to 1.13 and include all transportation conditions of the Chinese cities studied. After long-time observation of these conditions and using the analysis above, TSDR has been classified into four grades. Table 6 shows the relationship of the supply-demand ratio's value range and the transport conditions.

(3) Political Direction. The TSDR's four grades reflect only conditions during a particular period. In most Chinese cities, prevailing transport conditions are typically in a "scarce supply" or "short supply" condition, so pushing up transport supply has become the main attention focus of policymakers.

In Table 5, the Shenzhen TSDR increased 0.08 from 2012 to 2013 because the new urban road was $181 \mathrm{~km}$ long, the reformed road was $133 \mathrm{~km}$ long, and the new bus lanes were at least $100 \mathrm{~km}$ long. At the same time, the PCSDR values of bus, rail, and car are rising; road net expansion is therefore helpful in improving the service levels of transport system.

The value of Shenyang's TSDR also grew from 0.82 in 2010 to 0.89 in 2013, because the Shenyang metro line 1 (operational with $27.8 \mathrm{~km}$ and 22 stations) and line 2 (with $27.36 \mathrm{~km}$ and 21 stations), respectively, opened on September 27, 2011, and January 9, 2012. The formation of the Shenyang metro network improves the supply capacity of the transport system, but, at the same time, it changed the structure of transportation supply and demand. With more and more 
people choosing subway travel, the value of TSDR rose, while the values of bus, taxi, and car PCSDR dropped.

In most Chinese cities, it is feasible to think that pushing up transport supply can be adopted to increase the transport system's efficiency in the near future. However, in metropolitan areas, this approach has lost its foundation because of limited urban space, and reducing travel demand is palliative.

The worst metropolitan transport situation is described in Table 6. It is difficult to improve because it is rooted in various factors, such as greater and greater urban population, growing city areas, and uneven distribution of public facilities. To fundamentally optimize urban transport systems, traffic policies such as public transport priority, limited new vehicle registrations, vehicle bans, and rail transit network construction are not at work, and it is necessary to do more effective and feasible overall urban planning.

\section{Conclusion}

This paper has developed a method for estimating the TSDR and completed the following tasks: (1) the TSDR estimation model was constructed using VENSIM, after idealization based on system dynamic principles, and (2) the estimated TSDR results were analyzed by comparison with fifteen data sets about the eight cities' transport conditions refined through long-time observation.

The model can provide a basis for transport policy-making because it shows and quantifies the interaction between transport system supply and demand. The TSDR values symbolize the specific transport conditions and a synthetic result of economic, policy, and traffic development. At the same time, the contribution from traffic policies or measures to the TSDR can be evaluated, so investment projections and transport policies or measures can be ordered and screened.

The results of the model will be different for the various selected regions. The TSDR values in the paper reflect the collective transport condition of the cities, but the unequal population density of each region in a city leads to imbalance of their TSDR values. For example, in Guangzhou in 2012 the urban population density was 2060 persons per square kilometer, while values for Yuexiu and Nansha were 15112 and 795, and their TSDR's values were 0.52 and 0.91 during working-day peak hours, so the geographical scope for the model should be selected according to the particular regional goals for transport policies or measures.

Taken together, this paper sheds light on the nature of likely interaction between transportation supply and demand. However, much work remains to be done because the idealized transport system considered here has a certain distance from reality. Other aspects that clearly deserve further research involve bicycles and motorcycles on the urban road net and changes in the traveling intensity and modes.

\section{Conflict of Interests}

The authors declare that there is no conflict of interests regarding the publication of this paper.

\section{Acknowledgment}

This work was partially supported by National Natural Science Foundation of China (Project no. 51278158).

\section{References}

[1] W.-L. Jin, "A kinematic wave theory of lane-changing traffic flow," Transportation Research Part B: Methodological, vol. 44, no. 8-9, pp. 1001-1021, 2010.

[2] W.-L. Jin, "Continuous kinematic wave models of merging traffic flow," Transportation Research Part B: Methodological, vol. 44, no. 8-9, pp. 1084-1103, 2010.

[3] R. Liu, D. Van Vliet, and D. Watling, "Microsimulation models incorporating both demand and supply dynamics," Transportation Research A: Policy and Practice, vol. 40, no. 2, pp. 125-150, 2006.

[4] G. D. Wang, H. Shao, and D. X. Cao, "A mixed equilibrium traffic assignment model for transportation networks with ATIS under demand and supply uncertainties," in Proceedings of the International Joint Conference on Computational Sciences and Optimization (CSO '09), vol. 2, pp. 132-136, IEEE Computer Society, Sanya, China, April 2009.

[5] L. Xu and Z. Y. Gao, "Bi-objective urban road transportation discrete network design problem under demand and supply uncertainty," in Proceedings of the IEEE International Conference on Automation and Logistics (ICAL '08), pp. 1951-1955, IEEE, Qingdao, China, September 2008.

[6] M. E. Ben-Akiva, S. Gao, Z. Wei, and Y. Wen, "A dynamic traffic assignment model for highly congested urban networks," Transportation Research Part C: Emerging Technologies, vol. 24, pp. 62-82, 2012.

[7] C. Zhang, X. Chen, and A. Sumalee, "Robust Wardrop's user equilibrium assignment under stochastic demand and supply: expected residual minimization approach," Transportation Research B: Methodological, vol. 45, no. 3, pp. 534-552, 2011.

[8] C. Yuan, D. Wei, and H. Liu, "The impact of service refusal to the supply-demand equilibrium in taxicab market," in Proceedings of the 93rd Annual Meeting of the Transportation Research Board, Washington, DC, USA, January 2014.

[9] L. Budd, S. Ison, and T. Budd, "An empirical examination of the growing phenomenon of off-site residential car parking provision: the situation at UK airports," Transportation Research Part A: Policy and Practice, vol. 54, pp. 26-34, 2013.

[10] A. Bar-Yosef, K. Martens, and I. Benenson, "A model of the vicious cycle of a bus line," Transportation Research Part B: Methodological, vol. 54, pp. 37-50, 2013.

[11] G. Karon, "Travel demand and transportation supply modelling for agglomeration without transportation model," in Activities of Transport Telematics, J. Mikulski, Ed., pp. 284-293, Springer, New York, NY, USA, 2013.

[12] H. G. Kocken, I. Emiroglu, C. Guler et al., "The fractional transportation problem with interval demand, supply and costs," in Proceedings of the International Conference on Mathematical Sciences and Statistics (ICMSS '13), Z. K. Eshkuvatov, A. Kilicman, and L. W. June, Eds., pp. 339-344, American Institute of Physics, Melville, Australia, 2013.

[13] Y. Sheffi and C. Daganzo, "Hypernetworks and supply-demand equilibrium obtained with disaggregate demand models," Transportation Research Record, no. 673, pp. 113-121, 1978. 
[14] H. Al-Deek and E. B. Emam, "New methodology for estimating reliability in transportation networks with degraded link capacities," Journal of Intelligent Transportation Systems: Technology, Planning, and Operations, vol. 10, no. 3, pp. 117-129, 2006.

[15] R. H. Liu, T. May, and S. Shepherd, "On the fundamental diagram and supply curves for congested urban networks," Transportation Research Part A: Policy and Practice, vol. 45, no. 9, pp. 951-965, 2011.

[16] D.-Y. Lin, N. Eluru, S. T. Waller, and C. R. Bhat, "Integration of activity-based modeling and dynamic traffic assignment," Transportation Research Record, vol. 2076, pp. 52-61, 2008.

[17] L. M. Gardner, S. D. Boyles, and S. T. Waller, "Quantifying the benefit of responsive pricing and travel information in the stochastic congestion pricing problem," Transportation Research Part A: Policy and Practice, vol. 45, no. 3, pp. 202-218, 2011.

[18] S. Y. Liu, K. P. Triantis, and S. Sarangi, "A framework for evaluating the dynamic impacts of a congestion pricing policy for a transportation socioeconomic system," Transportation Research Part A: Policy and Practice, vol. 44, no. 8, pp. 596-608, 2010.

[19] M. Estrada, M. Roca-Riu, H. Badia, F. Robusté, and C. F. Daganzo, "Design and implementation of efficient transit networks: procedure, case study and validity test," Transportation Research Part A: Policy and Practice, vol. 45, no. 9, pp. 935-950, 2011.

[20] S. Y. Auyang, Foundations of Complex-system Theories, Cambridge University Press, Cambridge, UK, 1999.

[21] J.-F. Wang, H.-P. Lu, and H. Peng, "System dynamics model of urban transportation system and its application," Journal of Transportation Systems Engineering and Information Technology, vol. 8, no. 3, pp. 83-89, 2008.

[22] Z.-L. Cheng and X.-G. Qiu, "Overview of traffic system modeling research," in Proceedings of the 31st Chinese Control Conference (CCC '12), pp. 7279-7285, July 2012.

[23] D. Levinson and B. Yerra, "Self-organization of surface transportation networks," Transportation Science, vol. 40, no. 2, pp. 179-188, 2006.

[24] S. Shepherd, "A review of system dynamics models applied in transportation," Transportmetrica B: Transport Dynamics, vol. 2, no. 2, pp. 83-105, 2014.

[25] E. Cascetta, Transportation Systems Analysis: Models and Applications, Springer, 2009.

[26] Z.-A. Zhang and S.-W. Feng, "Game analysis of private cars and government-owned vehicles under road pricing regulation," Journal of Transportation Systems Engineering and Information Technology, vol. 2, article 013, 2008.

[27] Y.-H. Li, Z.-Z. Yuan, X.-H. Xie et al., "Analysis on trips characteristics of taxi in Suzhou based on OD Data," Journal of Transportation Systems Engineering and Information Technology, vol. 7, no. 5, pp. 85-89, 2007.

[28] Z. Xizhao, L. Canqi, and Y. Peikun, "Time-space sources of the network of urban road and space-capacity of traffic," Journal of Tongji University, vol. 24, no. 2, pp. 392-397, 1996.

[29] Z. X. L. Chaoyang, "Supply-demand models for time and space resources of urban road and their application," Journal of Shanghai Maritime University, vol. 3, p. 2, 1999.

[30] J. Odeck and S. Bråthen, "Travel demand elasticities and users attitudes: a case study of Norwegian toll projects," Transportation Research Part A: Policy and Practice, vol. 42, no. 1, pp. 77-94, 2008. 


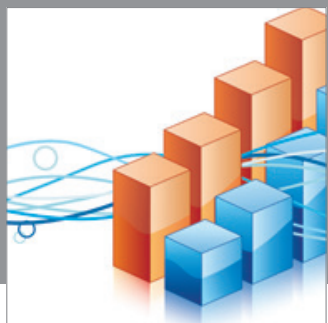

Advances in

Operations Research

mansans

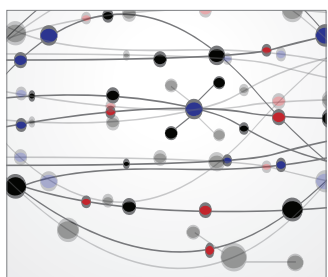

The Scientific World Journal
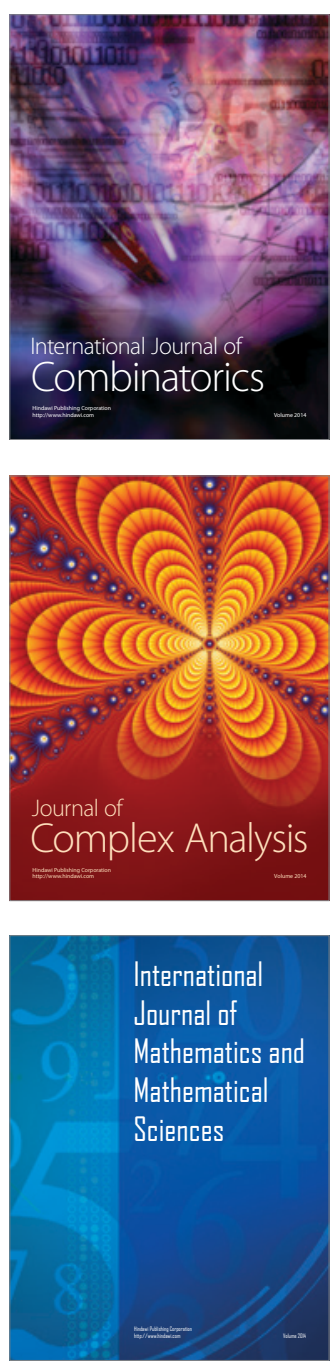
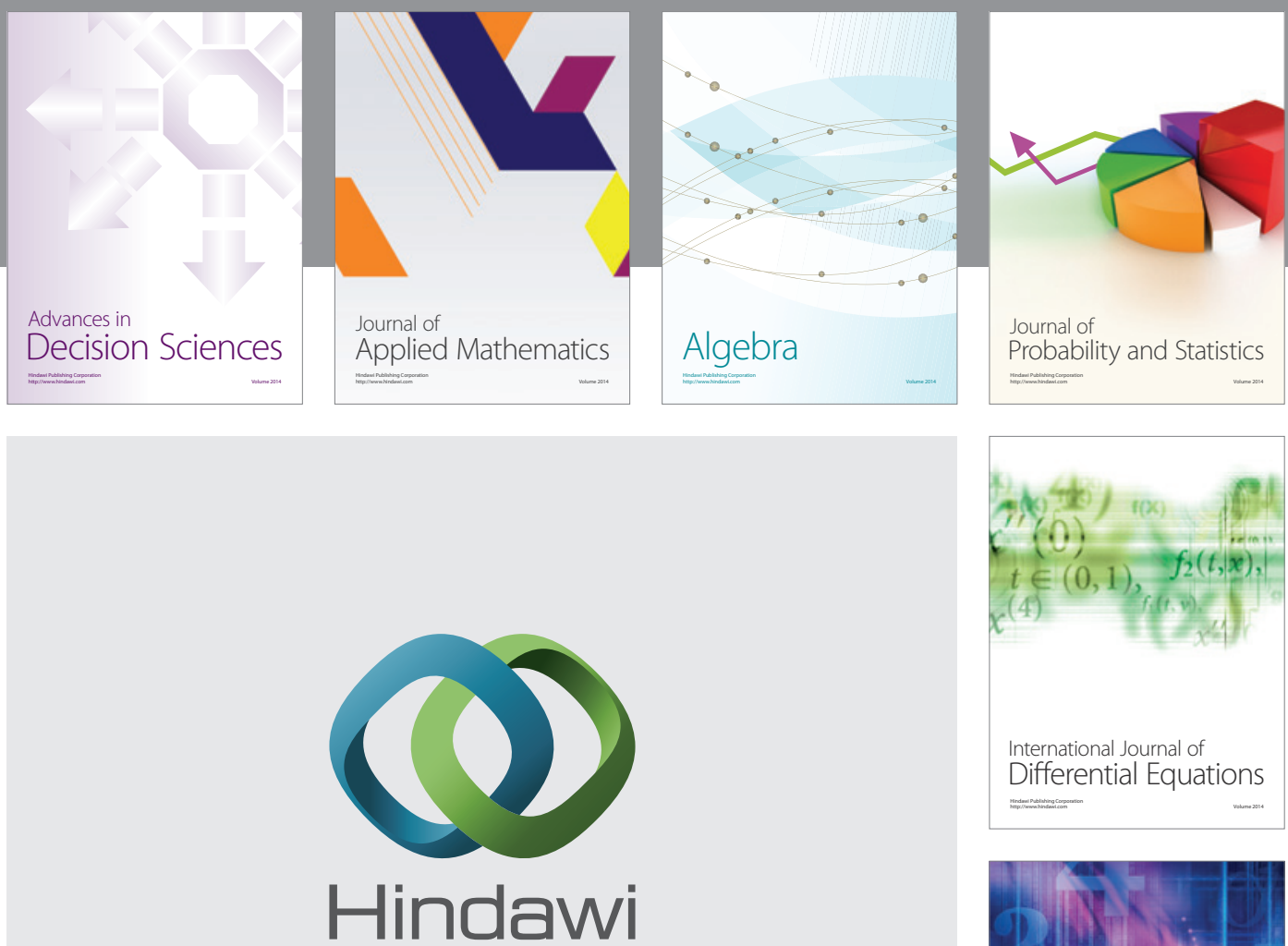

Submit your manuscripts at http://www.hindawi.com
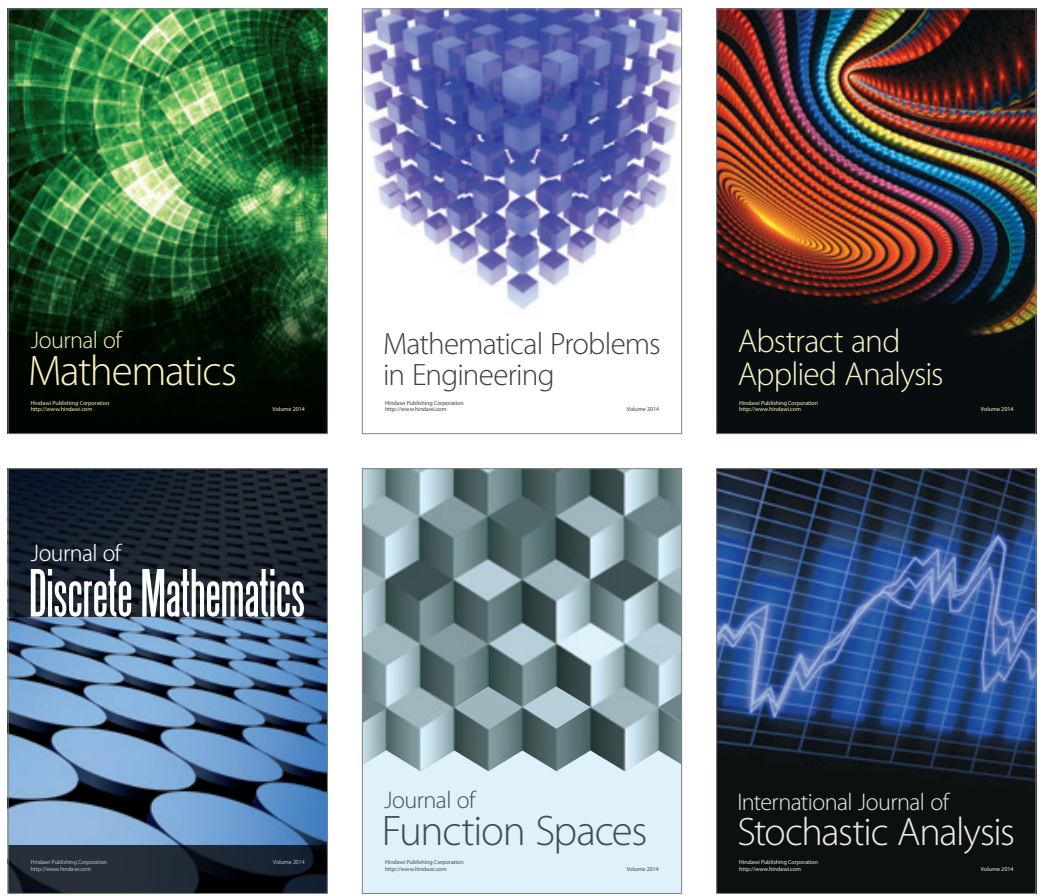

Journal of

Function Spaces

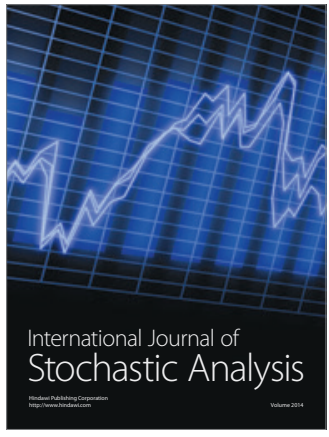

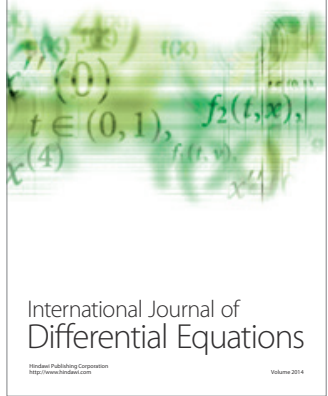
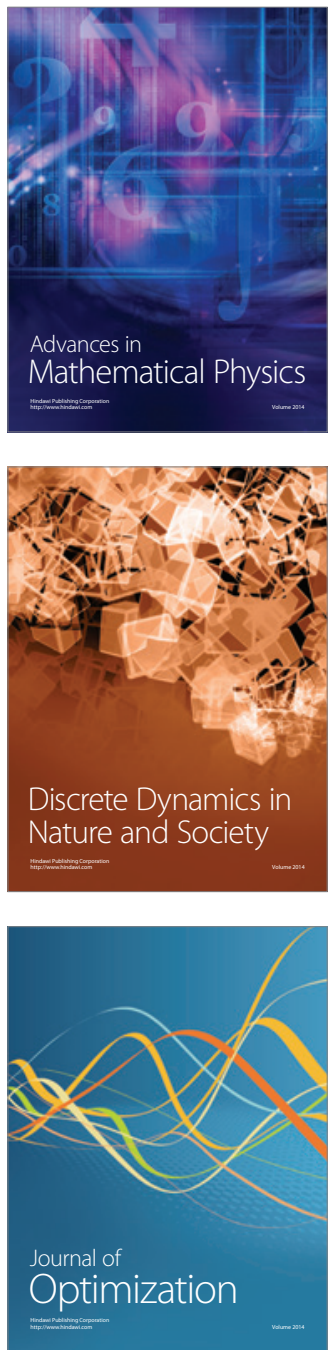